\title{
Endoplasmic Reticulum Stress and Neurodegeneration in Experimental Cerebral Malaria
}

\author{
Sripada Santosh Anand Phanithi Prakash Babu \\ Department of Biotechnology, School of Life Sciences, University of Hyderabad, Hyderabad, India
}

\begin{abstract}
Key Words
Cerebral malaria - Neuronal cell death · Protein kinase RNA-like endoplasmic reticulum kinase $\cdot$ Phosphorylated eukaryotic initiation factor $\alpha \cdot$ Activating transcription factor 4 - Caspase-12 - Binding immunoglobulin protein • $\mathrm{C} / \mathrm{EBP}$ homologous protein $(\mathrm{CHOP}) \cdot$ Fluoro-Jade B stain
\end{abstract}

\begin{abstract}
Experimental cerebral malaria (ECM) resulting from Plasmodium berghei ANKA $(\mathrm{PbA})$ infection in mice results in neuronal cell death. However, the precise mechanisms leading to neuronal cell death in ECM have not been fully elucidated. In the present study, we report the presence of endoplasmic reticulum (ER) stress markers and activation of the unfolded protein response (UPR) in the brain during the pathogenesis of ECM. Specific findings included activation of PKR-like ERkinase, inositol-requiring enzyme 1 and cleavage of activating transcription factor (ATF) 6 indicating the activation of all three major arms of the UPR. Further, we found changes in the protein levels of phosphorylated eukaryotic initiation factor $\alpha$ (p-elF2 $\alpha)$, ATF4, growth arrest and DNA damage-inducible protein 34, B cell lymphoma protein 2 (BCL-2), $\mathrm{BCL}-2$-associated $\mathrm{X}$ protein, caspase-7, cleavage of caspase-3, and caspase-12. Our results demonstrate that ER stress-induced neuronal cell death in PbA-infected mice is associated
\end{abstract}

with the expression of the pro-apoptotic molecule CHOP and downregulation of anti-apoptotic ER quality control molecules binding immunoglobulin protein, calreticulin and calnexin. Further $\mathrm{CHOP}$ was found to be localized in neurons and plays an essential role in neuronal cell death as revealed by our Fluoro-Jade $B$ double staining. These results implicate an imbalance between ER stress-mediated pro-apoptotic and anti-apoptotic/survival signalling as a critical determinant of neuronal cell death in ECM.

Copyright $\odot 2012$ S. Karger AG, Base

\section{Introduction}

Cerebral malaria (CM) is the life-threatening complication of Plasmodium falciparum infection in humans, responsible for more than 1 million deaths annually [1]. Cerebral dysfunction becomes evident through a variety of symptoms, including extreme lethargy and febrile convulsions and can progress to coma and death in approximately $20 \%$ of cases [2]. Although a number of studies have described the neurological complications of human $\mathrm{CM}$, the pathogenesis remains controversial. Apart from post-mortem brain studies, an experimental murine model, induced by the infection of susceptible mice with Plasmodium berghei ANKA ( $\mathrm{PbA})$, has been used to fur-

\section{KARGER}

E-Mail karger@karger.ch www.karger.com/nsg

\section{(c) 2012 S. Karger AG Basel 1424-862X/13/0212-0099\$38.00/0 \\ Karger \\ Open access \\ This is an Open Access article licensed under the terms} of the Creative Commons Attribution-NonCommercialNoDerivs 3.0 License (www.karger.com/OA-license), applicable to the online version of the article only. Distribution for non-commercial purposes only.
Phanithi Prakash Babu

Department of Biotechnology, School of Life Sciences

University of Hyderabad

Gachibowli, Hyderabad 500046 (India)

E-Mail ppbsl@uohyd.ernet.in 
ther understand the pathogenesis of CM [3]. Studies with this model have suggested that experimental CM (ECM) complications are multifactoral involving activation of platelets, upregulation of pro-inflammatory cytokines and endothelial cell adhesion molecules, disruption of the blood-brain barrier, infiltration of leucocytes together with the mechanical blockage of microvessels by the monocytes and parasitized erythrocytes (PRBC) [4]. The pathological features of the fatal stage include PRBC and monocyte adhesion to cerebral vascular endothelial cells, oedema, petechial hemorrhages, glial activation and neuronal cell death in the central nervous system [5-9]. The mechanisms leading to cell death are complex, and several pathways have been implicated, including mitochondrial dysfunction, calcium-activated kinases, phosphatases and proteases, caspases and c-Jun $\mathrm{N}$-terminal kinases (JNK) $[8,10-13]$. Though the events central to tumour necrosis factor and interleukin are activated during ECM [14], to our understanding no reports exist on the role of endoplasmic reticulum (ER) stress proteins during cell death in the brain.

The ER is a cell organelle which plays a pivotal role in the synthesis, folding, posttranslational modifications and trafficking of secretory and membrane proteins, calcium storage and release, lipid biogenesis and apoptosis. Perturbations in ER functioning may lead to accumulation of misfolded proteins in the ER lumen, and the ER in turn initiates an adaptive response known as the unfolded protein response (UPR) that protects the cell against the accumulation of misfolded proteins [15]. However, if the ER stress is excessive and prolonged, these adaptive responses fail to compensate and the UPR leads to cell death by both caspase-dependent and caspase-independent pathways $[16,17]$. The UPR is initiated by the binding of the ER chaperone binding immunoglobulin protein/glucose-regulated protein $78(\mathrm{BiP} / \mathrm{GRP} 78)$ to the misfolded proteins. Under normal physiological conditions, BiP forms a complex and suppresses the activity of 3 proximal ER-resident stress sensors: protein kinase Rlike ER kinase (PERK), inositol-requiring enzyme 1 (IRE1) and activating transcription factor 6 (ATF6) [16]. During ER stress, BiP binds to misfolded proteins thereby releasing PERK, IRE1 and ATF6 from the complex. Upon its release from $\mathrm{BiP}, \mathrm{PERK}$ is activated by homodimerization and autophosphorylation, and subsequently the kinase domain of PERK phosphorylates eIF $2 \alpha$ (p-eIF2 $\alpha$ ), thereby shutting down global protein synthesis [18]. However, phosphorylation of eIF $2 \alpha$ can also lead to selective translation of activating transcription factor 4 (ATF4) which in turn activates the transcription of prosurvival genes such as GRP78 and GRP94, genes that are resistant to oxidative stress and genes that are involved in amino acid metabolism and transport $[19,20]$. IRE1 is activated by dimerization and trans-autophosphorylation upon its release from BiP [21]. Activated IRE1 splices XBP1 mRNA, resulting in a translational frameshift and formation of potent transcriptional activator, inducing the transcription of ER stress-responsive genes [16]. ATF6 is an ERresident protein which binds to $\mathrm{BiP}$ under normal physiological conditions. However, during ER stress BiP binds to unfolded proteins releasing ATF6 which translocates to the Golgi apparatus and is cleaved by site 1 and site 2 proteases to release transcription factors [22]. The released transcription factors migrate to the nucleus and induce the transcription of ER chaperone proteins such as GRP78, GRP94, protein disulphide isomerase, and the transcription factors $\mathrm{CHOP}$ and $\mathrm{X}$ box-binding protein 1 (XBP1) $[16,23]$. Further the role of ER stress pathways in mediating neuronal cell death has been well documented in several neurodegenerative diseases like Alzheimer's and Parkinson's disease, amyotrophic lateral sclerosis, transmissible spongiform encephalopathies and ischaemia [24].

The present study examines the role of ER stress proteins in modulating neuronal cell death in ECM, with particular emphasis laid on the PERK-eIF2 $\alpha$ axis. Our study shows for the first time that CHOP mediates neuronal cell death in murine CM.

\section{Materials and Methods}

\section{Induction of CM in Mice}

All the protocols followed for the use of animal experimentation were approved by the institutional as well as national ethical committee guidelines. Six- to 8-week-old C57BL/6J mice of either sex (approx. $20 \mathrm{~g}$ body weight, $\mathrm{n}=4$ per group) were inoculated intraperitoneally with $10^{6} \mathrm{PRBC}$, suspended in $200 \mu \mathrm{l}$ of phosphate-buffered saline (PBS, $\mathrm{pH}$ 7.4). Uninfected mice of the same age and sex were used as negative controls. The animals infected with the $\mathrm{PbA}$ strain showed behavioural changes around day 5 after inoculation followed by cerebral symptoms like paralysis, hemiplegia, convulsions and coma eventually leading to death. The parasitaemia was monitored by preparing periodic blood smears from day 1 of parasite inoculation and was typically between 15 and $20 \%$ at the time of sacrifice. The duration between parasite inoculation and sacrifice of terminally ill animals was approximately 6-12 days.

\section{Preparation of Tissue Lysates}

Mouse brain tissues were homogenized in 5 volumes of radioimmunoprecipitation assay buffer containing $50 \mathrm{mM}$ Tris- $\mathrm{HCl}$ (pH 8.0), 150 mM NaCl, 1 mM EDTA, 0.4\% deoxycholate, $1 \%$ NP- 
40 containing protease inhibitors including $2 \mu \mathrm{g} / \mathrm{ml}$ leupeptin, $2 \mu \mathrm{g} / \mathrm{ml}$ aprotinin, $1 \mathrm{~mm}$ phenylmethylsulphonylfluoride and phosphatase inhibitors including $10 \mathrm{~mm} \beta$-glycerophosphate, 10 $\mathrm{mM} \mathrm{NaF}$ and $0.3 \mathrm{mM} \mathrm{Na}_{3} \mathrm{VO}_{4}$. The lysate was sonicated for $2 \mathrm{~min}$ and centrifuged at $14,000 \mathrm{~g}$ for $15 \mathrm{~min}$ at $4^{\circ} \mathrm{C}$. The supernatant was collected as whole tissue lysate and frozen at $-80^{\circ} \mathrm{C}$ before use. Protein concentrations were determined by the method of Bradford (Bio-Rad).

\section{Western Immunoblotting}

Western immunoblotting was performed according to the procedure published earlier [13]. Briefly, $50 \mu \mathrm{g}$ of tissue lysates were separated by sodium dodecylsulphate polyacrylamide gel electrophoresis and transferred onto nitrocellulose membranes and probed with primary antibodies for $1 \mathrm{~h}$. Then membranes were incubated with secondary antibodies conjugated to alkaline phosphatase (anti-rabbit and anti-mouse IgG conjugated to alkaline phosphatase obtained from Genei Pvt Ltd., Bangalore, India), and immunoreactivity was visualized by incubating the membranes with BCIP-NBT solution (Genei Pvt Ltd.). Immunoreactivity was analysed quantitatively using Image J software (NIH). The primary antibodies used in these experiments included rabbit polyclonal antibodies raised against eIF2- $\alpha$, growth arrest and DNA damage-inducible protein 34 (GADD34), BiP, calregulin, calnexin (Santa Cruz Biotechnology); phospho-IRE1 (p-IRE1), ATF4 (Abcam); p-eIF2 $\alpha$ (Epitomics), phospho-PERK (p-PERK), caspase-3, B cell lymphoma protein 2 (BCL-2), BCL-2-associated $\mathrm{X}$ protein (BAX), cleaved caspase-7, caspase-12 (Cell Signaling Technology); CHOP/GADD153 (Pierce) and mouse monoclonal antibodies raised against ATF6 (Abcam).

\section{Histopathology}

Formalin-fixed, paraffin-embedded mouse brain sections were deparaffinized in xylene, rehydrated in alcohol series and stained with haematoxylin and eosin (HE) for histological analysis.

\section{Immunohistochemistry and Double Immunofluorescence}

Analysis

For immunohistochemistry, infected and control mouse brains were perfused first with $0.9 \%$ saline solution followed by $4 \%$ paraformaldehyde in $0.1 \mathrm{M} \mathrm{PBS}, \mathrm{pH} 7.4$, and were embedded in paraffin. Paraffin-embedded mouse brains were sectioned horizontally $(5 \mu \mathrm{m})$ by an automated rotary microtome (Leica), deparaffinized in xylene, passed through graded alcohols and further rehydrated in PBS. Antigen retrieval was carried out by microwaving sections in $10 \mathrm{~mm}$ citrate buffer, $\mathrm{pH}$ 6.0, for $10 \mathrm{~min}$. Sections were then treated with $3 \% \mathrm{H}_{2} \mathrm{O}_{2}$ for 10 min to inhibit endogenous peroxidase followed by incubation with serum for $1 \mathrm{~h}$ at room temperature in a humid chamber. Primary antibody (1:100 dilution of rabbit polyclonal antibodies against p-eIF2 $\alpha$ and $\mathrm{CHOP}$ ) was diluted in blocking solution and incubated overnight at $4^{\circ} \mathrm{C}$. Peroxidase-conjugated secondary antibody was used for $1 \mathrm{~h}$ at room temperature followed by Tris-buffered saline washes $(3 \times 5 \mathrm{~min}$ each). Diaminobenzidine in buffer was used till sections developed colour. Sections were then counterstained with haematoxylin for $10 \mathrm{~s}$ and washed with $\mathrm{dH}_{2} \mathrm{O}$ followed by dehydration in graded ethanol and xylene and coverslipped with DPX mount.

ER Stress in ECM
For double immunofluorescence analysis, the same procedure was followed except that the sections were not pretreated with $1 \%$ hydrogen peroxide. Double immunofluorescence analysis was performed by incubating sections in a cocktail of primary antibodies [rabbit polyclonal p-eIF2 $\alpha$ 1:100 dilution with mouse monoclonal synaptophysin (Abcam) 1:100 dilution and rabbit polyclonal CHOP (1:100) dilution with mouse monoclonal synaptophysin (Abcam) 1:100 dilution] overnight at $4^{\circ} \mathrm{C}$. The sections were washed in PBS and then incubated in fluorochrome-conjugated secondary antibodies 1:100 for $1 \mathrm{~h}$ at room temperature and further incubated with diamidinophenylindole and mounted using Vectashield (Vector Laboratories). The sections were visualized using a Leica confocal microscope.

\section{Fluoro-Jade B Staining}

For Fluoro-Jade B staining, deparaffinized sections were subjected to $100 \%$ ethanol for $10 \mathrm{~min}$ followed by basic alcohol (1\% sodium hydroxide in $80 \%$ alcohol) for $5 \mathrm{~min}$. This was followed by immersing the sections in $70 \%$ alcohol for 2 min and doubledistilled water for $2 \mathrm{~min}$. Sections were then immersed in potassium permanganate solution for $10 \mathrm{~min}$, washed once with PBS for $2 \mathrm{~min}$, and immersed in Fluoro-Jade B solution ( $0.0004 \%$ concentration) for $30 \mathrm{~min}$ at room temperature. After staining, the sections were washed 3 times with double-distilled water, cleared with xylene, air dried and coverslipped using DPX (Fluka). For colocalization studies of CHOP with Fluoro-Jade B, deparaffinized sections were washed once with PBS for $5 \mathrm{~min}$, microwaved in citrate buffer for $15 \mathrm{~min}$, blocked with $5 \%$ goat serum and probed with CHOP antibody for $1 \mathrm{~h}$, followed by 3 PBS washes. Sections were then incubated in secondary antibody, washed thrice with PBS and subjected to graded alcohol series. Sections were pretreated for $2 \mathrm{~min}$ with $0.06 \%$ potassium permanganate, rinsed in double-distilled water for $3 \mathrm{~min}$ and immersed in Fluoro-Jade B solution $(0.0004 \%$ concentration) for $30 \mathrm{~min}$ at room temperature. After this step, sections were washed thrice with PBS for 5 min each, cleared with xylene and air dried on a slide warmer at $50^{\circ} \mathrm{C}$, mounted with DPX and coverslipped. Later, sections were analysed under a Leica confocal microscope.

\section{Data Analysis}

Data are reported as means \pm SEM of $n$ experiments. All parameters were compared using a two-tailed Student's t test between infected and control animals. A level of $\mathrm{p}<0.05$ was considered statistically significant and was determined using Sigma Plot 2000 for Windows version 6.00 (SPSS Inc., Ill., USA).

\section{Results}

As shown in figure 1 a, all the infected mice succumbed to the disease and died by day 12 after infection with a median survival of 7.5 days $(\mathrm{p}<0.0001)$ often with parasitaemia not exceeding $15 \%$ (data not shown), whereas all the uninfected control mice had $100 \%$ survival. HE staining of brain sections taken from $\mathrm{PbA}$-infected animals (fig. 1c, e and g) showed distinct neurological lesions, with parenchymal microhaemorrhages, cells with 


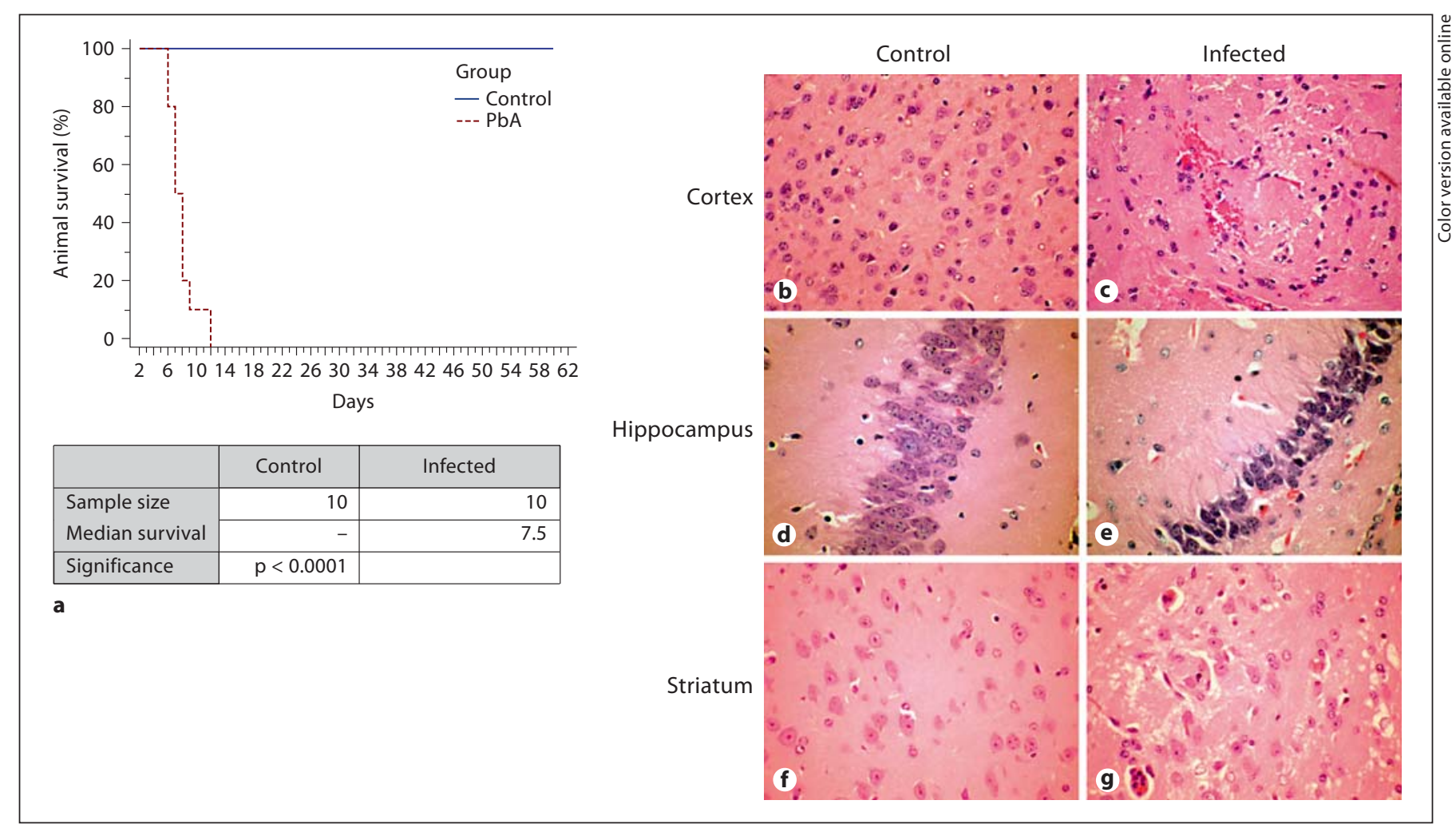

Fig. 1. a Kaplan-Meier survival curve analysis showing C57BL/6J mice $(\mathrm{n}=10)$ inoculated intraperitoneally with $10^{6}$ PRBC which died by day 12 after infection with a median survival of 7.5 days $(\mathrm{p}<0.0001)$, while all uninfected controls $(\mathrm{n}=10)$ had $100 \%$ survival. Observation of animal survival experiments was done in a masked manner so as to avoid bias toward any group of animals. b-g HE staining of brain sections encompassing the cortex (c),

irreversible damage, shrinkage of the nucleus, vacuolization of the cytoplasm with distinct apoptotic morphology, disruption of vessel walls and adherence of leucocytes to the vessel walls. In contrast, brain sections taken from uninfected controls (fig. $1 \mathrm{~b}, \mathrm{~d}$ and $\mathrm{f}$ ) had a healthy parenchyma and clear vessels with no haemorrhage.

To investigate whether $\mathrm{PbA}$ infection leads to the activation of ER stress sensors, we performed Western blot analyses using antibodies against the phosphorylated forms of PERK and IRE1. Significant increases in immunoreactivity for $\mathrm{p}-\operatorname{PERK}(\mathrm{p}=0.006)$ and $\mathrm{p}-\operatorname{IRE} 1(\mathrm{p}=0.05)$ were seen in $\mathrm{PbA}$-infected mouse brains as compared to controls. We further assessed the cleavage status of ATF6 in both $\mathrm{PbA}$-infected and control mouse brains using an antibody which detects spliced and unspliced versions of ATF6. As shown in figure 2, ATF6p50 (the activated cytosolic form of ATF6) protein levels were significantly increased in PbA-infected mouse brains as compared to un- hippocampus (e) and striatum (g), taken from $\mathrm{PbA}$-infected animals showing widespread neurological lesions, cells with apoptotic morphology, petechial haemorrhages and blood vessels clogged with leucocytes and PRBC. Sections taken from control animals (b, d and f) have a healthy parenchyma, with no vascular clogging or haemorrhages. Figures were taken at a magnification of $\times 60$. infected controls $(\mathrm{p}<0.001)$. Taken together our results indicate the activation of all the three major arms of the ER stress signalling pathway.

Since activation of PERK induces the phosphorylation of eIF $2 \alpha$, we next checked the status of eIF $2 \alpha$ phosphorylation. As shown in figure $3 \mathrm{a}$, there is a significant increase in the p-eIF $2 \alpha$ levels in the infected brains compared to controls $(\mathrm{p}<0.001)$, while unphosphorylated eIF $2 \alpha$ levels remained the same. In addition, we performed immunohistochemistry on brain sections encompassing the cortex, hippocampus and striatum of $\mathrm{PbA}$-infected animals or uninfected controls, to confirm the induction of p-eIF $2 \alpha$. In control mouse brain sections (fig. $3 b, d$ and f), p-eIF2 $\alpha$ immunoreactivity was poorly distributed. However, in infected mouse brain sections (fig. 3c, e and g), signals for p-eIF $2 \alpha$ increased in intensity and were thus correlated with our Western blot results. Furthermore, double immunofluorescent analysis of $\mathrm{p}$ - 
Fig. 2. a Immunoblot analysis of p-PERK, p-IRE1, ATF6 and $\beta$ actin in the control and infected mouse brains. An equal amount of protein was electrophoresed by sodium dodecylsulphate polyacrylamide gel electrophoresis and transferred to nitrocellulose membranes and probed with primary antibody to $\mathrm{p}$-PERK, $\mathrm{p}$ IRE1, ATF6 and $\beta$-actin. $\beta$-Actin was used as loading control. The result is representative of 4 independent experiments with similar results. The lanes $\mathrm{C}$ and I indicate uninfected control and $\mathrm{PbA}-$ infected mouse brains sacrificed on day 7 after infection, respectively. b-d Densitometric analysis (arbitrary units, AU) showing significant increases in the levels of p-PERK, p-IRE1 and ATF6 in infected samples as compared to their respective controls. ${ }^{*} \mathrm{p}<$ $0.05,{ }^{*} \mathrm{p}<0.001$ : significant difference relative to the corresponding control.

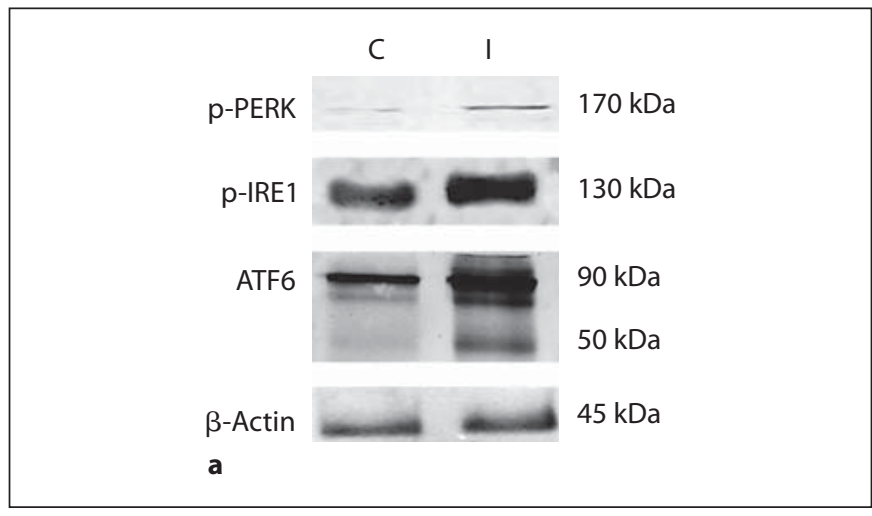

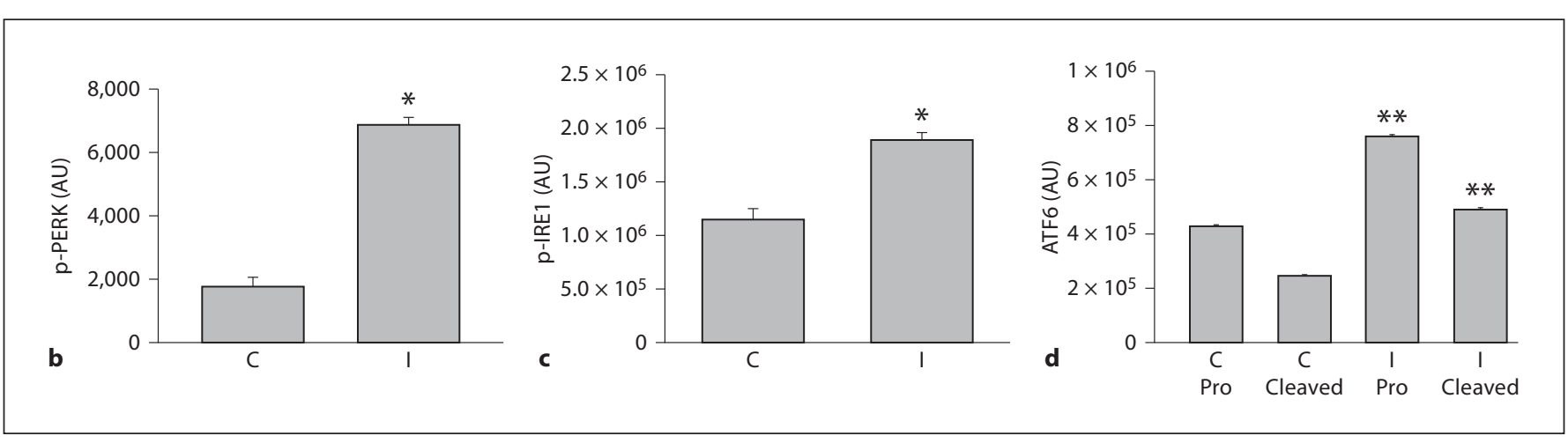

eIF2 $\alpha$ with synaptophysin, a neuronal marker (fig. $3 \mathrm{~h}-\mathrm{k}$ ) revealed neuronal induction of p-eIF $2 \alpha$ in infected mouse brain sections, implying that neurons are the principal cell types in which p-eIF $2 \alpha$ is activated in murine CM.

To further gain insight into the downstream effectors of the PERK-eIF $2 \alpha$ branch of the UPR during PbA infection, we asked if factors which are normally activated by high levels of p-eIF2 $\alpha$, such as ATF4 and GADD34, are expressed under these conditions. In our immunoblot analyses (fig. 4) we found significant increases in the expression of both ATF4 and GADD34 ( $\mathrm{p}=0.002$ and 0.005 , respectively) in infected mouse brains as compared to controls indicating activation of the PERK-eIF $2 \alpha$ branch of the UPR during PbA infection. To confirm the activation of IRE1, we checked the status of spliced XBP1 (XBP1s) by immunoblot analysis. Our results revealed a significant upregulation of XBP1s $(\mathrm{p}=0.008)$ in infected brains as compared to controls implying the activation of the IRE1 axis of the ER stress pathway (fig. 4). We next investigated the status of ER chaperones such as BiP, calregulin and calnexin which are prosurvival and are expressed during the UPR and ER stress (fig. 5). Western blot analysis revealed a significant downregulation of calregulin $(\mathrm{p}=0.02)$ and calnexin $(\mathrm{p}=0.002)$ in infected mice when compared to controls. On the other hand, although we observed the downregulation of BiP levels in infected mice compared to controls, the decrease is not that significant $(\mathrm{p}=0.073)$.

All the three major arms, i.e. PERK, IRE1 and ATF6 of the UPR and ER stress signalling pathway, converge on the elements in the CHOP promoter region to induce $\mathrm{CHOP}$ expression. To test this, we first performed Western blot analysis and later the bands are quantitated by densitometry (fig. 6a). Our results show a prominent increase in the levels of CHOP protein in infected samples $(p=0.009)$ but in control samples it is barely detectable. Immunohistochemistry of brain sections using $\mathrm{CHOP}$ antibody revealed a robust increase in immunoreactivity with distinct nuclear localization in all the three brain regions in infected sections (fig. 6c, e and g) but not in control brain sections (fig. $6 \mathrm{~b}, \mathrm{~d}$ and $\mathrm{f}$ ). Further double immunofluorescence labelling on infected brain sections revealed colocalization of CHOP (fig. 6j) with synaptophysin (fig. 6i), a neuronal marker suggesting the neuronal expression of $\mathrm{CHOP}$ in the infected brain.

Moreover, several studies have shown $\mathrm{CHOP}$ playing a role as a pro-apoptotic molecule induced by ER stress [16, $17,23]$ and earlier studies from our laboratory have shown 


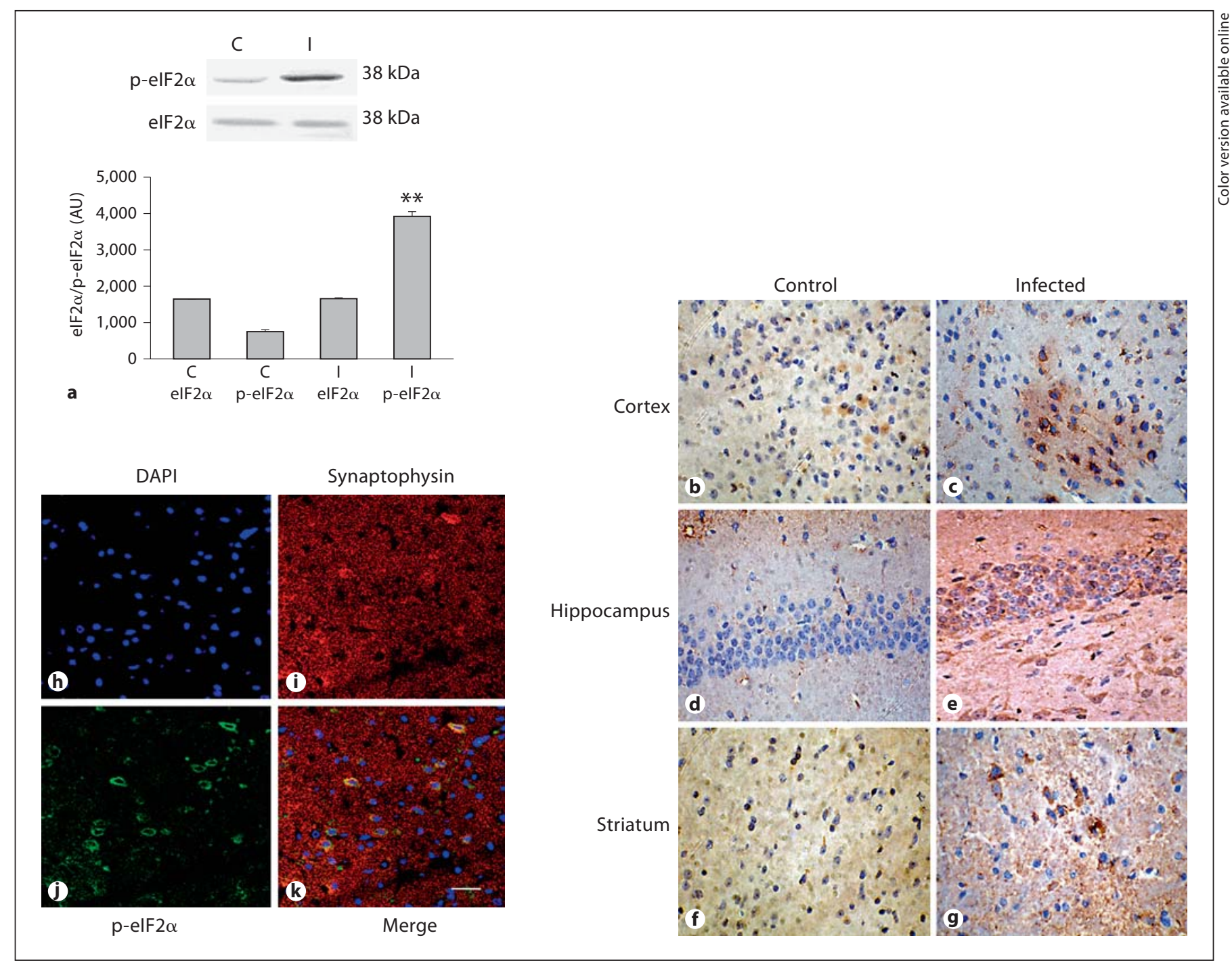

Fig. 3. a Immunoblot analysis of p-eIF $2 \alpha$ and $\operatorname{IF} 2 \alpha$ in the control and infected mouse brains. The result is representative of 4 independent experiments with similar results. The lanes $\mathrm{C}$ and I indicate uninfected control and $\mathrm{PbA}$-infected mouse brains sacrificed on day 7 after infection, respectively. Densitometric analysis (vertical bar graph; arbitrary units, AU) showing significant increases in the levels of p-eIF2 $\alpha$ in infected samples as compared to controls while the levels of eIF $2 \alpha$ remained the same in both groups. ${ }^{* *} \mathrm{p}<0.001$ : significant difference relative to the corresponding control. b-g Immunohistochemistry. In control mouse brain sections, p-eIF2 $\alpha$ immunoreactivity was barely detectable (b, $\mathbf{d}$ and $\mathbf{f})$. However, in infected mouse brain sections there is a robust increase in p-eIF $2 \alpha$ immunoreactivity in all three brain regions (c, e and $\mathbf{g}$ ). Pictures were taken at a magnification of $\times 60$. $\mathbf{h}-\mathbf{k}$ Double immunofluorescence analysis. Double immunostaining of p-eIF $2 \alpha(\mathbf{j})$ and synaptophysin (i) showed neuronal induction of p-eIF $2 \alpha$ in infected brain sections (overlay, $\mathbf{k}$ ). Diamidinophenylindole (DAPI) was used as nuclear counterstain (h). Photomicrographs shown here in this figure are representative of 3 individual animals from each group. Bar $=40 \mu \mathrm{m}$. that the pathology of ECM manifests neuronal apoptosis [10-13]. To substantiate our results, we checked the levels of pro-apoptotic proteins like BAX, caspase-3, active caspase-7, caspase-12 and anti-apoptotic BCL-2. Immunoblotting with caspase- 3 antibody revealed significant increases in the levels of cleaved caspase- $3(p<0.001)$ in the infected brain (fig. 7). Further, $\mathrm{PbA}$ infection resulted in the elevated protein levels of BAX $(\mathrm{p}=0.002)$, active caspase-7 $(\mathrm{p}<0.001)$ and active caspase- $12(\mathrm{p}<0.001)$ in the infected brain (fig. 7). On the other hand, anti-apoptotic BCL-2 levels in infected brains were barely detectable indicating predominance of apoptosis in the infected sam- 
Fig. 4. a Immunoblot analysis of spliced and unspliced XBP1 (XBP1s and XBP1u, respectively), ATF4 and GADD34 in the control and infected mouse brains. $\beta$-Actin was used as loading control. The result is representative of 4 independent experiments with similar results. The lanes $\mathrm{C}$ and I indicate uninfected control and $\mathrm{PbA}$-infected mouse brains sacrificed on day 7 after infection, respectively. b-d Densitometric analysis (arbitrary units, AU) showing significant increases in the levels of XBP1s, ATF4 and GADD34 in infected samples as compared to their respective controls. ${ }^{*} \mathrm{p}<0.05$ : significant difference relative to the corresponding control.

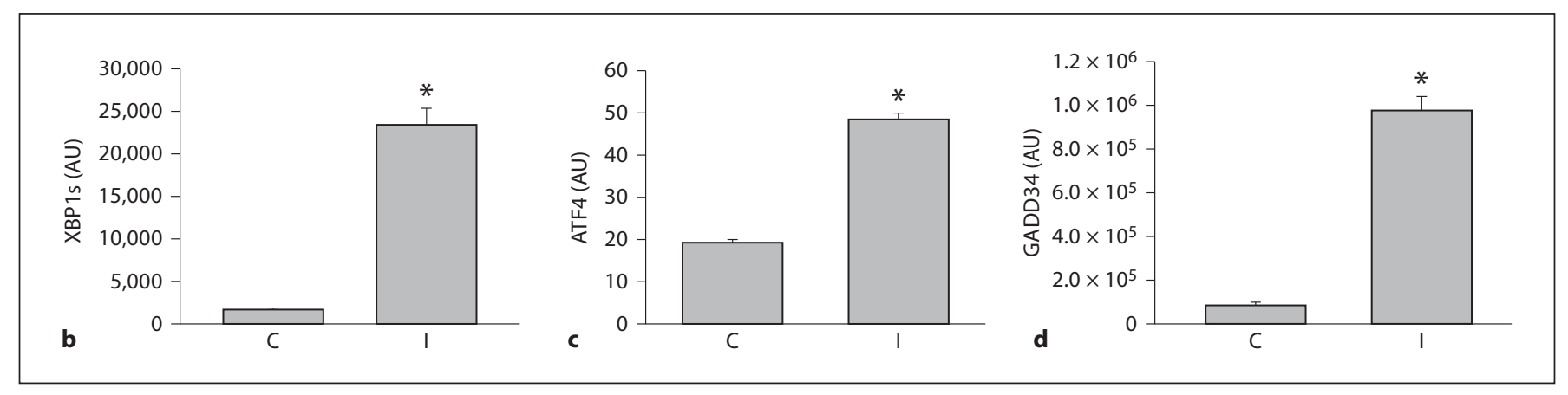

Fig. 5. a Immunoblot analysis of $\mathrm{BiP}$, calregulin and calnexin in the control and infected mouse brains. $\beta$-Actin was used as loading control. The result is representative of 4 independent experiments with similar results. The lanes $\mathrm{C}$ and I indicate uninfected control and PbA-infected mouse brains sacrificed on day 7 after infection, respectively. b-d Densitometric analysis (arbitrary units, AU) showing significant decreases in the levels of calregulin and calnexin in infected samples as compared to their respective controls. Changes in BiP levels in the infected samples as compared to controls were not found to be significant. ${ }^{*} \mathrm{p}<0.05$ : significant difference relative to the corresponding control.

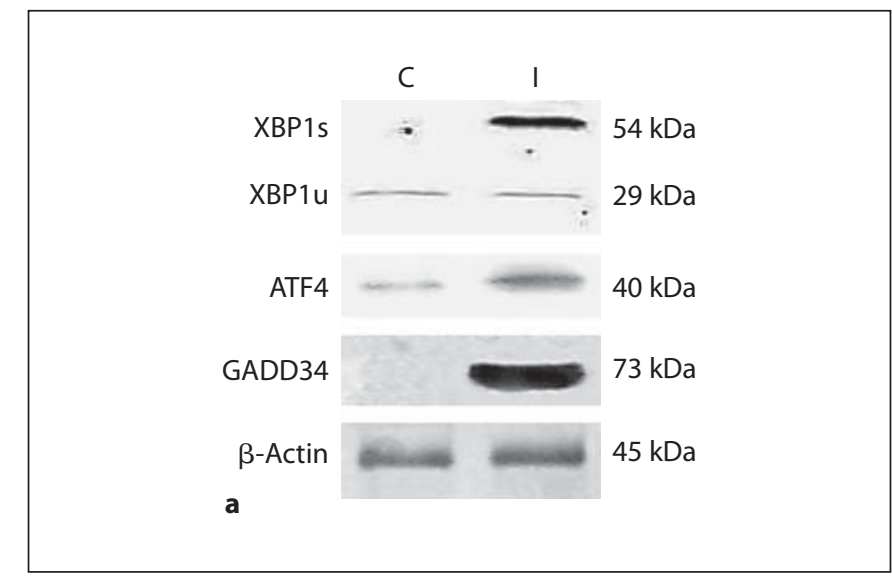

a

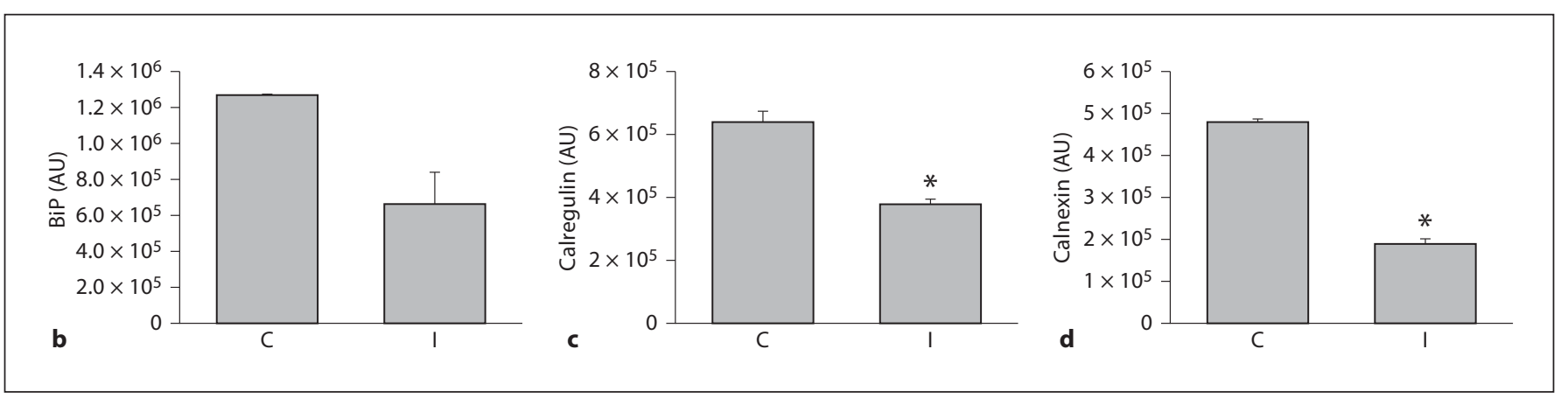




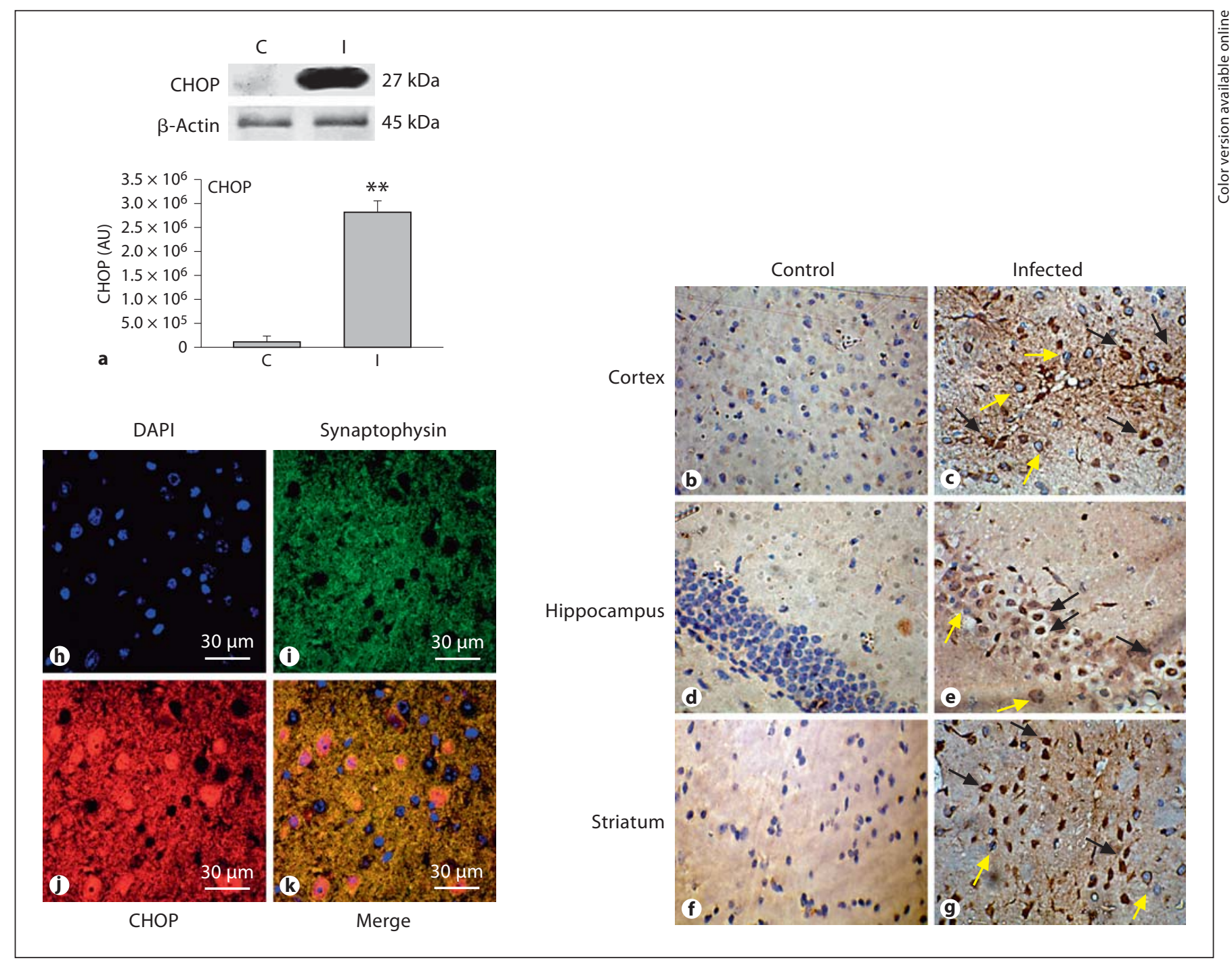

Fig. 6. a Immunoblot analysis of $\mathrm{CHOP}$ in the control and infected mouse brains. The result is representative of 4 independent experiments with similar results. The lanes $\mathrm{C}$ and I indicate uninfected control and PbA-infected mouse brains sacrificed on day 7 after infection, respectively. Densitometric analysis (vertical bar graph; arbitrary units, AU) showing significant increases in the levels of $\mathrm{CHOP}$ in infected samples as compared to controls. $\beta$-Actin was used as loading control. ${ }^{* *} \mathrm{p}<0.001$ : significant difference relative to the corresponding control. $\mathbf{b}-\mathbf{g}$ Immunohistochemistry. In control mouse brain sections, CHOP immunoreactivity was barely detectable (b, $\mathbf{d}$ and $\mathbf{f})$. However, in infected mouse brain sections, there is a marked increase in CHOP immunoreactivity in all three brain regions with nuclear localization (as shown by black arrows in panels $\mathbf{c}$, e and $\mathbf{g}$; in contrast, yellow arrows indicate cytosolic CHOP immunoreactivity; colours shown in the online version only). Pictures were taken at a magnification of $\times 60$. $\mathbf{h}-\mathbf{k}$ Double immunofluorescence analysis. Double immunostaining of CHOP (j) and synaptophysin (i) showed neuronal induction of CHOP in infected brain sections (overlay, k). Diamidinophenylindole was used as nuclear counterstain (h). Note nuclear localization of $\mathrm{CHOP}$ in $\mathbf{k}$. Photomicrographs shown here in this figure are representative of 3 individual animals from each group. ples. To confirm neuronal cell death in PbA-infected mice, we stained the sections with Fluoro-Jade B, a novel fluorescent marker which binds to dying neurons [25]. Our results revealed several Fluoro-Jade B-positive cells in all three brain regions in infected samples (fig. 8c, $g$ and k) but not in control brain sections (fig. 8a, e and i) indicating widespread neuronal cell death in PbA-infected murine brains. Moreover, colocalization studies of CHOP with Fluoro-Jade $\mathrm{B}$ on infected mouse brain sections (fig. $8 \mathrm{~m}, \mathrm{n}$ and o) clearly showed that $\mathrm{CHOP}$ is upregu- 

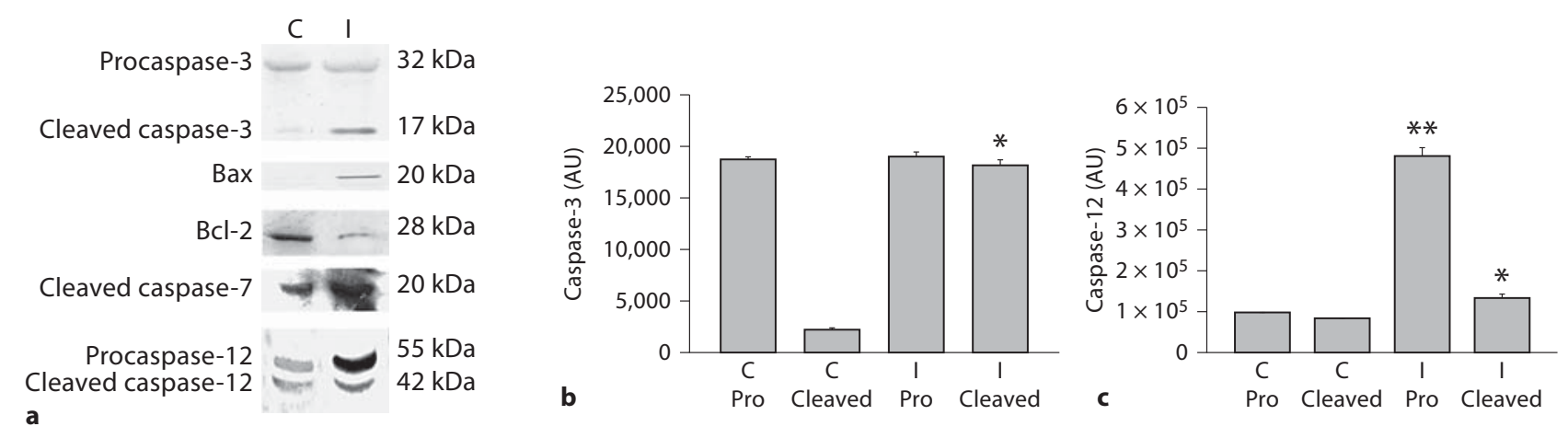

Fig. 7. a Immunoblot analysis of caspase-3, BCL-2, BAX, active caspase- 7 and caspase- 12 in the control and infected mouse brains. $\beta$-Actin was used as loading control. The result is representative of 4 independent experiments with similar results. The lanes $\mathrm{C}$ and $\mathrm{I}$ indicate uninfected control and $\mathrm{PbA}$-infected mouse brains sacrificed on day 7 after infection, respectively. b, c Densi-

lated in degenerating neurons following $\mathrm{PbA}$ infection. Together, these results proved unambiguously that $\mathrm{CHOP}$ is involved in neuronal cell death in murine CM.

\section{Discussion}

The murine CM model has provided important insights into the pathogenesis of CM and enabled potential targets for modulation to be identified for study in humans. C57BL/6J mice infected with $\mathrm{PbA}$ develop neurological signs and symptoms typical of human CM and die within 6-12 days after infection [3]. Studies with this model have identified the upregulation of several proapoptotic mediators as major cause of neuronal cell death during the course of infection [8-13]. An overwhelming evidence points out the activation of inflammatory pathways, upregulation of cytokines such as tumour necrosis factor $\alpha, \gamma$-interferon, interleukins 1,6 and 8 and PRBC sequestration during the pathophysiology of CM [4]. Further, sequestration results in reduced blood flow leading to tissue hypoxia and hypoglycaemia [26], which in turn causes protein misfolding and ER stress. Although there is growing evidence underlying the role of the UPR and ER stress in several neurodegenerative disorders [24], there is no data currently available as to which of the three possible branches of the UPR are activated, or the kinetics of activation or the extent of their involvement in neuronal cell death in ECM. tometric analysis (arbitrary units, AU) showing significant increases in the levels of cleaved caspase- 3 and significant increases in the levels of total and cleaved versions of caspase-12 in infected samples as compared to their respective controls. ${ }^{*} \mathrm{p}<0.05$, ${ }^{* *} \mathrm{p}<0.001$ : significant difference relative to the corresponding control).

To this end, we performed Western blot analyses, and for the first time our results showed the induction of $\mathrm{p}$ PERK and p-IRE1 and cleavage of ATF6 in infected mouse brains but not in uninfected controls indicating the activation all three branches of the UPR. Our results are in agreement with earlier studies of brain ischaemia/ reperfusion and other neurodegenerative disorders which implicate the activation of multiple pathways of the UPR following insult [24]. However, we emphasized the role of the PERK-eIF $2 \alpha$ axis in this study mainly because our aim here was to investigate a well-established pathway of translation arrest and to provide a deeper insight into the mechanisms by which the PERK-eIF $2 \alpha$ axis mediates neuronal cell death in ECM.

Along with hypoglycaemia which is known to occur in CM [26], depletion of ER calcium stores is known to activate PERK $[27,28]$. Further, a direct proof of evidence linking disturbances in neuronal calcium homeostasis to PERK activation is lacking in the ECM model. However, supporting evidence in the form of calpain activation owing to altered calcium homeostasis in pathological manifestation of the disease is well established [12]. Activation of PERK leads to eIF $2 \alpha$ phosphorylation, thereby shutting off mRNA translation and reducing the protein load on the ER. In this study, we evaluated PbA-induced alterations in both eIF $2 \alpha$ phosphorylation and eIF $2 \alpha$ protein levels by Western blotting using the respective antibodies. While there is no change in the levels of eIF $2 \alpha$ protein, $\mathrm{p}$-eIF $2 \alpha$ levels increased significantly in infected 


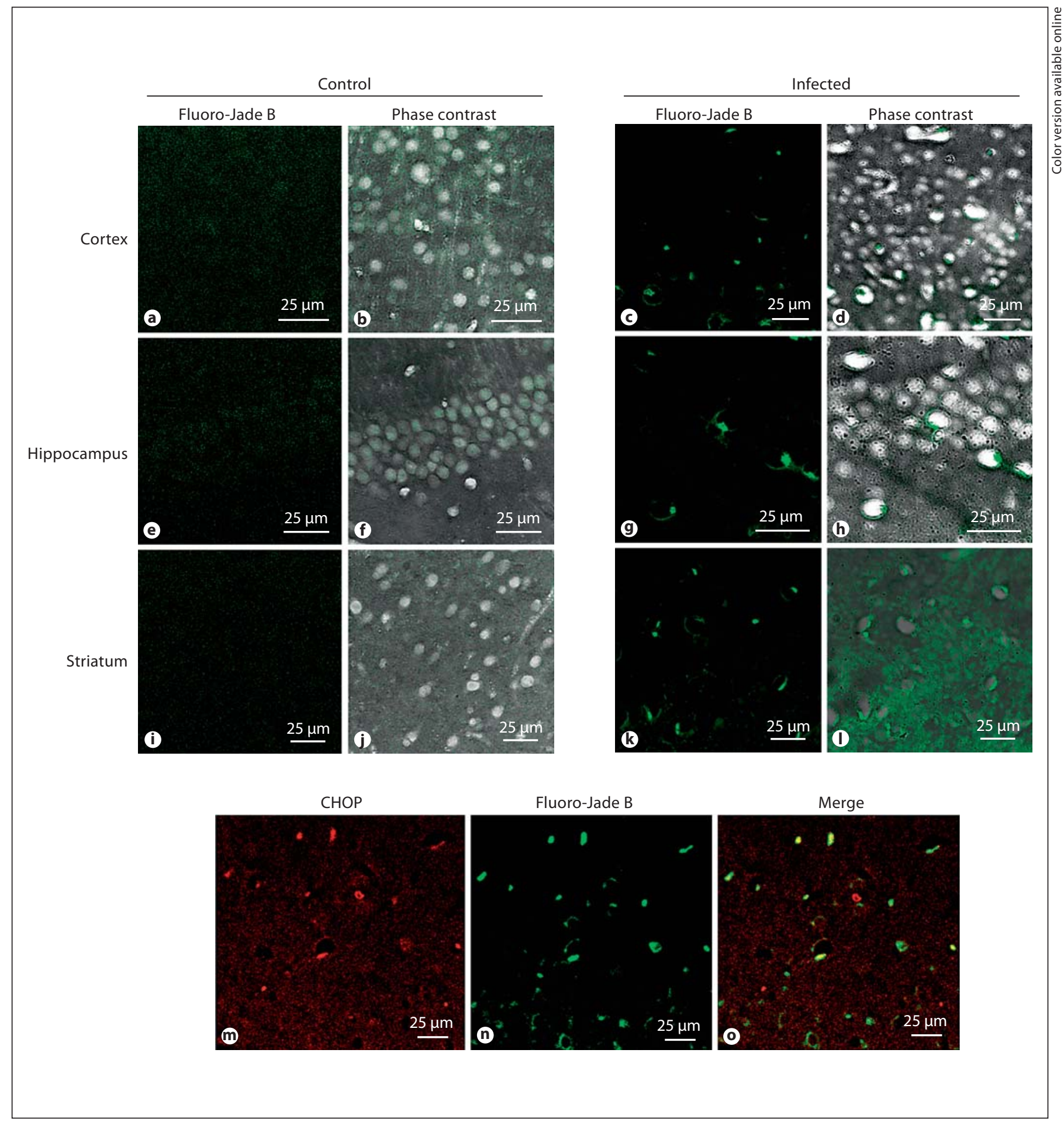

Fig. 8. Paraffin-embedded sections of both control (a, e and $\mathbf{i})$ and $\mathrm{PbA}$-infected mouse brain sections $(\mathbf{c}, \mathbf{g}$ and $\mathbf{k})$ were stained for Fluoro-Jade B. While control sections stained very little for Fluoro-Jade $B$, infected sections have significantly higher numbers of Fluoro-Jade B-positive cells in all three regions. Panels $\mathbf{b}, \mathbf{f}$ and $\mathbf{j}$ and $\mathbf{d}, \mathbf{h}$ and $\mathbf{I}$ are phase-contrast images of control (a, $\mathbf{e}$ and $\mathbf{i})$ and infected (c, $\mathbf{g}$ and $\mathbf{k})$ panels, respectively. Double-label staining of CHOP $(\mathbf{m})$ and Fluoro-Jade B (n) showed that CHOP-positive cells were also positive for Fluoro-Jade B (o). Photomicrographs shown here in this figure are representative of 3 individual animals from each group. 
mice as compared to controls. Further we performed immunohistochemistry to determine whether there was any regional difference in the expression of p-eIF $2 \alpha$. We selected the cortex, hippocampus and striatum, the three different neuro-anatomical regions that control movement because $\mathrm{CM}$ affects movement and coordination in terminally ill mice with symptoms ranging from (but not limited to) stupor, hemiplegia, dysplegia, paraplegia, coma and finally death. Robust increases in immunoreactivity for p-eIF $2 \alpha$ were observed in the cortex, hippocampus and striatum indicating that all three regions are equally vulnerable to ER stress, and in fact this regional vulnerability coincides with neuronal cell death as observed in our HE and Fluoro-Jade B staining. We further performed p-eIF $2 \alpha /$ synaptophysin colocalization experiments in infected mouse brain sections to confirm the neuronal induction of $\mathrm{p}$-eIF $2 \alpha$. Our results show that $\mathrm{p}$ eIF $2 \alpha$ was significantly upregulated in neurons, and taking into account the pattern of Fluoro-Jade B staining we conclude that neurons are particularly vulnerable to ER stress-mediated cell death.

eIF $2 \alpha$ phosphorylation was followed by the induction of the transcription factor ATF4 and GADD34, both genes being specific targets of the PERK/eIF $2 \alpha$ pathway. GADD34 is a regulatory subunit of protein phosphatase 1 , which is required for eIF $2 \alpha$ dephosphorylation and recovery from a shut-off of total protein synthesis in response to ER stress [29]. In our results we found distinct increases in both ATF4 and GADD34 emphasizing the point that the PERK/eIF2 $\alpha$ pathway is activated in ECM. Increased levels of p-eIF2 $\alpha$ and GADD34 observed in infected mice throw light on the dynamic stress response involving regulation of eIF $2 \alpha$ kinases and phosphatases. Increased GADD34 levels in infected animals also support the notion that the increase in the levels of p-eIF $2 \alpha$ is due to elevated activity of the upstream kinase and not due to decreased activity of phosphatase.

While ATF4 on one hand induces the transcription of prosurvival genes such as GRP78, GRP94 and genes that are involved in amino acid metabolism and transport, on the other hand it also leads to the transcription of CHOP/ GADD153 which is a pro-apoptotic ER stress marker. In fact, the PERK-eIF2 $\alpha$ signalling pathway directly regulates the transcriptional arm of the UPR, affecting both the pro- and anti-apoptotic components [30]. In this connection we performed Western blot analyses of $\mathrm{BiP}$ and $\mathrm{CHOP}$, and our results show a decrease in BiP levels and a corresponding increase in $\mathrm{CHOP}$ levels suggesting that the pro-apoptotic component of the PERK-eIF2 $\alpha$ signalling pathway is dominant over its anti-apoptotic counter- part in the PbA-infected mice. This fact is further strengthened by our results wherein we also found the downregulation of calreticulin and calnexin, the two ERresident prosurvival chaperones $[31,32]$ in infected mice as compared to controls. Our results are in agreement with earlier studies where BiP expression was reduced while $\mathrm{CHOP}$ expression was increased in the late phase of permanent middle cerebral artery occlusion in mice [33]. Thus, in light of these observations we conclude that in ECM, ER stress accompanied by failure of an adaptive response, may eventually result in apoptotic cell death.

$\mathrm{CHOP}$ is a transcription factor that translocates to the nucleus after its activation. In fact, all three axes of the ER stress pathway converge on CHOP induction [34], and it is one of the highest inducible genes during ER stress as revealed by micro-array analysis [35]. Numerous pieces of evidence reveal that overexpression of $\mathrm{CHOP}$ or microinjection of CHOP into cells promotes apoptosis [36-38], while overexpression of $\mathrm{BiP}$ attenuates $\mathrm{CHOP}$-induced apoptosis [39]. Similarly, mice deficient in CHOP showed reduced apoptosis in response to ER stress $[38,40]$. Our results from $\mathrm{CHOP}$ immunohistochemistry show that $\mathrm{CHOP}$ immunoreactivity is robust in all three brain regions of the infected mouse brain as compared to controls. Further CHOP is localized exclusively to the nucleus and $\mathrm{CHOP} /$ synaptophysin colocalization experiments revealed that $\mathrm{CHOP}$ is expressed in neurons in infected mice. Moreover, $\mathrm{CHOP} /$ Fluoro-Jade B dual staining confirms that CHOP is involved in neuronal cell death in $\mathrm{PbA}$-infected mice. Taken together, our results highlight the importance of CHOP-mediated neuronal cell death in ECM.

Apart from its intrinsic ribonuclease activity, IRE1 also has a Ser/Thr kinase domain which once activated is involved in ER stress-mediated cell death [16]. In fact, modulation of UPR signalling via IRE1 $\alpha$ is also dependent on its association with pro-apoptotic members of the BCL-2 family BAX and BCL-2 antagonist/killer [41]. Our results, in conjunction with this previous study, show the activation of IRE1, induction of XBP1s, upregulation of BAX, downregulation of BCL-2 and cleavage of caspase-3 indicating the ER stress-mediated apoptotic pathway in $\mathrm{PbA}$-infected mouse brains. Activated IRE1 $\alpha$ also mediates apoptosis via its interaction with the cytoplasmic domain of TRAF2 and activation of JNK via the IRE1 $\alpha$ TRAF2-ASK1-JNK signalling pathway [16, 42]. In fact, Liu et al. [43] recently demonstrated the IRE1 $\alpha$-ASK1JNK-mediated pro-apoptotic pathway in the hippocampus of patients with chronic epilepsy. Earlier, we have demonstrated the activation and involvement of JNK in 
mediating neuronal cell death in the ECM model [13]. Taken together, these data implicate a role of IRE1 $\alpha$ in neuronal apoptosis in $\mathrm{PbA}$-infected mice.

Unlike activated IRE1 which plays a major role in apoptosis in ER-stressed cells, activation of ATF6 is prosurvival aimed to counteract ER stress [23]. Moreover, in a recent study it was reported that ischaemia activates ATF6 and induces ER stress-responsive genes [44]. Furthermore, sequestration of PRBC, attachment of monocytes to cerebral endothelia, cerebral oedema and increase in brain lactate result in ischaemic conditions [45] which may provide a plausible explanation for the activation of ATF6 in the PbA-infected murine brain.

Caspase-12 is present on the cytoplasmic side of the ER and mediates cell death associated with ER stress. Caspase-12 is activated either by calpain owing to $\mathrm{Ca}^{2+} \mathrm{im}$ balances [46] or it is activated by the classical TRAF2IRE1-JNK pathway [47] or it is activated by caspase-7 [48]. Our results show the activation of caspase- 12 in infected animals, but at this point of time we cannot exactly de- lineate as to which of these pathways are involved in caspase-12 activation. In fact, we have reported earlier the activation of calpains and JNK $[12,13]$ in murine malaria. Further, we have also checked the levels of active caspase-7 in this study which suggests that activation of caspase-12 in ECM could be synergistic involving calpains, TRAF2-IRE1-JNK and also caspase-7.

In summary the results presented here show for the first time activation of multiple apoptotic ER stress pathways which could shed new light onto the mechanisms underlying the relationship between ER stress, the UPR and the cell death programme in ECM.

\section{Acknowledgements}

The authors would like to acknowledge funding from DBT, CSIR, ICMR, DST and DST nano UoH project and DBT-CREB, New Delhi, India. We thank CSIR for fellowship to Anand Sripada.

\section{References}

1 Miller LH, Good MF, Milon G: Malaria pathogenesis. Science 1994;264:1878-1883.

-2 Idro R, Jenkins NE, Newton CR: Pathogenesis, clinical features, and neurological outcome of cerebral malaria. Lancet Neurol 2005;4:827-840.

3 De Souza JB, Riley EM: Cerebral malaria: the contribution of studies in animal models to our understanding of immunopathogenesis. Microbes Infect 2002;4:291-300.

4 Van der Heyde HC, Nolan J, Combes V, Gramaglia I, Grau GE: A unified hypothesis for the genesis of cerebral malaria: sequestration, inflammation and hemostasis leading to microcirculatory dysfunction. Trends Parasitol 2006;22:503-508.

5 Pongponratn E, Turner GD, Day NP, Phu NH, Simpson JA, Stepniewska K, Mai NT, Viriyavejakul P, Looareesuwan S, Hien TT, Ferguson DJ, White NJ: An ultrastructural study of the brain in fatal Plasmodium falciparum malaria. Am J Trop Med Hyg 2003;69: 345-359.

6 Potter S, Chan-Ling T, Ball HJ, Mansour H, Mitchell A, Maluish L, Hunt NH: Perforin mediated apoptosis of cerebral microvascular endothelial cells during experimental cerebral malaria. Int J Parasitol 2006;36:485496.

7 Medana IM, Hunt NH, Chan-Ling T: Early activation of microglia in the pathogenesis of fatal murine cerebral malaria. Glia 1997;19: 91-103.
8 Lackner P, Burger C, Pfaller K, Heussler V, Helbok R, Morandell M, Broessner G, Tannich E, Schmutzhard E, Beer R: Apoptosis in experimental cerebral malaria: spatial profile of cleaved caspase- 3 and ultrastructural alterations in different disease stages. Neuropathol Appl Neurobiol 2007;33:560-571.

9 Wiese L, Kurtzhals JA, Penkowa M: Neuronal apoptosis, metallothionein expression and proinflammatory responses during cerebral malaria in mice. Exp Neurol 2006; 200:216-226.

10 Kumar KA, Babu PP: Mitochondrial anomalies are associated with the induction of intrinsic cell death proteins-Bcl(2), Bax, cytochrome-c and $\mathrm{p} 53$ in mice brains during experimental fatal murine cerebral malaria. Neurosci Lett 2002;329:319-323.

- 11 Kumar KA, Rajgopal Y, Pillai U, Babu PP: Activation of nuclear transcription factorkappa $B$ is associated with the induction of inhibitory kappa B kinase-beta and involves differential activation of protein kinase $\mathrm{C}$ and protein tyrosine kinases during fatal murine cerebral malaria. Neurosci Lett 2003;340:139-142.

12 Shukla M, Rajgopal Y, Babu PP: Activation of calpains, calpastatin and spectrin cleavage in the brain during the pathology of fatal murine cerebral malaria. Neurochem Int 2006;48:108-113.

13 Anand SS, Babu PP: c-Jun N terminal kinases (JNK) are activated in the brain during the pathology of experimental cerebral malaria. Neurosci Lett 2011;488:118-122.
14 Medana IM, Chaudhri G, Chan-Ling T, Hunt NH: Central nervous system in cerebral malaria: 'innocent bystander' or active participant in the induction of immunopathology? Immunol Cell Biol 2001;79:101120.

15 Kaufman RJ: Stress signaling from the lumen of the endoplasmic reticulum: coordination of gene transcriptional and translational controls. Genes Dev 1999;13:1211-1233.

16 Kim I, Xu W, Reed JC: Cell death and endoplasmic reticulum stress: disease relevance and therapeutic opportunities. Nat Rev Drug Discov 2008;7:1013-1030.

17 Rao RV, Ellerby HM, Bredesen DE: Coupling endoplasmic reticulum stress to the cell death program. Cell Death Differ 2004;11: 372-380.

18 Harding HP, Zhang Y, Ron D: Protein translation and folding are coupled by an endoplasmic-reticulum-resident kinase. Nature 1999;397:271-274.

19 Lu PD, Harding HP, Ron D: Translation reinitiation at alternative open reading frames regulates gene expression in an integrated stress response. J Cell Biol 2004;167: 27-33.

20 Harding HP, Zhang Y, Zeng H, Novoa I, Lu PD, Calfon M, Sadri N, Yun C, Popko B, Paules R, Stojdl DF, Bell JC, Hettmann T, Leiden JM, Ron D: An integrated stress response regulates amino acid metabolism and resistance to oxidative stress. Mol Cell 2003; 11:619-633. 
-21 Bertolotti A, Zhang Y, Hendershot LM, Harding HP, Ron D: Dynamic interaction of BiP and ER stress transducers in the unfoldedprotein response. Nat Cell Biol 2000;2:326332.

-22 Haze K, Yoshida H, Yanagi H, Yura T, Mori $\mathrm{K}$ : Mammalian transcription factor ATF6 is synthesized as a transmembrane protein and activated by proteolysis in response to endoplasmic reticulum stress. Mol Biol Cell 1999; 10:3787-3799.

23 Szegezdi E, Logue SE, Gorman AM, Samali A: Mediators of endoplasmic reticulum stress-induced apoptosis. EMBO Rep 2006; 7:880-885.

24 Lindholm D, Wootz H, Korhonen L: ER stress and neurodegenerative diseases. Cell Death Differ 2006;13:385-392.

25 Schmued LC, Hopkins KJ: Fluoro-Jade B: a high affinity fluorescent marker for the localization of neuronal degeneration. Brain Res 2000;874:123-130.

26 Marsh K, Forster D, Waruiru C, Mwangi I, Winstanley M, Marsh V, Newton C, Winstanley P, Warn P, Peshu N, et al: Indicators of life-threatening malaria in African children. N Engl J Med 1995;332:1399-1404.

27 Brostrom CO, Brostrom MA: Calcium-dependent regulation of protein synthesis in intact mammalian cells. Annu Rev Physiol 1990;52:577-590.

28 Prostko CR, Brostrom MA, Malara EM, Brostrom CO: Phosphorylation of eukaryotic initiation factor (eIF) 2 alpha and inhibition of eIF-2B in GH3 pituitary cells by perturbants of early protein processing that induce GRP78. J Biol Chem 1992;267: 16751-16754.

29 Novoa I, Zeng H, Harding HP, Ron D: Feedback inhibition of the unfolded protein response by GADD34-mediated dephosphorylation of eIF2alpha. J Cell Biol 2001;153: 1011-1022.

30 Luo S, Baumeister P, Yang S, Abcouwer SF, Lee AS: Induction of Grp78/BiP by translational block: activation of the Grp78 promoter by ATF4 through and upstream ATF/CRE site independent of the endoplasmic reticulum stress elements. J Biol Chem 2003;278: 37375-37385.
31 Liu H, Bowes RC 3rd, van de Water B, Sillence C, Nagelkerke JF, Stevens JL: Endoplasmic reticulum chaperones GRP78 and calreticulin prevent oxidative stress, $\mathrm{Ca}^{2+}$ disturbances, and cell death in renal epithelial cells. J Biol Chem 1997;272:21751-21759.

32 Rosenbaum EE, Hardie RC, Colley NJ: Calnexin is essential for rhodopsin maturation, $\mathrm{Ca}^{2+}$ regulation, and photoreceptor cell survival. Neuron 2006;49:229-241.

- 33 Morimoto N, Oida Y, Shimazawa M, Miura M, Kudo T, Imaizumi K, Hara H: Involvement of endoplasmic reticulum stress after middle cerebral artery occlusion in mice. Neuroscience 2007;147:957-967.

4 Oyadomari S, Mori M: Roles of CHOP/ GADD153 in endoplasmic reticulum stress. Cell Death Differ 2004;11:381-389.

35 Okada T, Yoshida H, Akazawa R, Negishi M, Mori K: Distinct roles of activating transcription factor 6 (ATF6) and double-stranded RNA-activated protein kinase-like endoplasmic reticulum kinase (PERK) in transcription during the mammalian unfolded protein response. Biochem J 2002;366:585594.

-36 Matsumoto M, Minami M, Takeda K, Sakao Y, Akira S: Ectopic expression of CHOP (GADD153) induces apoptosis in M1 myeloblastic leukemia cells. FEBS Lett 1996;395: 143-147.

37 Maytin EV, Ubeda M, Lin JC, Habener JF: Stress-inducible transcription factor $\mathrm{CHOP} /$ gadd153 induces apoptosis in mammalian cells via p38 kinase-dependent and -independent mechanisms. Exp Cell Res 2001;267: 193-204.

- 38 Oyadomari S, Takeda K, Takiguchi M, Gotoh T, Matsumoto M, Wada I, Akira S, Araki E, Mori M: Nitric oxide-induced apoptosis in pancreatic beta cells is mediated by the endoplasmic reticulum stress pathway. Proc Natl Acad Sci USA 2001;98:1084510850.

39 Wang XZ, Lawson B, Brewer JW, Zinszner H, Sanjay A, Mi LJ, Boorstein R, Kreibich G, Hendershot LM, Ron D: Signals from the stressed endoplasmic reticulum induce $\mathrm{C} /$ EBP-homologousprotein (CHOP/GADD153). Mol Cell Biol 1996;16:4273-4280.
40 Zinszner H, Kuroda M, Wang X, Batchvarova N, Lightfoot RT, Remotti H, Stevens JL, Ron D: CHOP is implicated in programmed cell death in response to impaired function of the endoplasmic reticulum. Genes Dev 1998;12:982-995.

41 Hetz C, Bernasconi P, Fisher J, Lee AH, Bassik MC, Antonsson B, Brandt GS, Iwakoshi NN, Schinzel A, Glimcher LH, Korsmeyer SJ. Proapoptotic BAX and BAK modulate the unfolded protein response by a direct interaction with IRE1alpha. Science 2006;312: 572-576.

42 Urano F, Wang X, Bertolotti A, Zhang Y, Chung P, Harding HP, Ron D: Coupling of stress in the ER to activation of JNK protein kinases by transmembrane protein kinase IRE1. Science 2000;287:664-666.

43 Liu G, Guo H, Guo C, Zhao S, Gong D, Zhao $Y$ : Involvement of IRE1 $\alpha$ signaling in the hippocampus in patients with mesial temporal lobe epilepsy. Brain Res Bull 2011;84:94102.

44 Doroudgar S, Thuerauf DJ, Marcinko MC Belmont PJ, Glembotski CC: Ischemia activates the ATF6 branch of the endoplasmic reticulum stress response. J Biol Chem 2009; 284:29735-29745.

45 Sanni LA, Rae C, Maitland A, Stocker R, Hunt NH: Is ischemia involved in the pathogenesis of murine cerebral malaria? Am J Pathol 2001;159:1105-1112.

46 Nakagawa T, Yuan J: Cross-talk between two cysteine protease families. Activation of caspase- 12 by calpain in apoptosis. J Cell Biol 2000;150:887-894.

-47 Yoneda T, Imaizumi K, Oono K, Yui D, Gomi F, Katayama T, Tohyama M: Activation of caspase-12, an endoplastic reticulum (ER) resident caspase, through tumor necrosis factor receptor-associated factor 2-dependent mechanism in response to the ER stress. J Biol Chem 2001;276:13935-13940.

-48 Rao RV, Hermel E, Castro-Obregon S, del Rio G, Ellerby LM, Ellerby HM, Bredesen DE: Coupling endoplasmic reticulum stress to the cell death program. Mechanism of caspase activation. J Biol Chem 2001;276: 33869-33874. 